\title{
Investigation into stress wave propagation in metal foams
}

\author{
Lang Li, Pu Xue ${ }^{\mathrm{a}}$, and Yue Chen \\ School of Aeronautics, Northwestern Polytechnical University, Xi' an 710072, PR China
}

\begin{abstract}
The aim of this study is to investigate stress wave propagation in metal foams under high-speed impact loading. Threedimensional Voronoi model is established to represent real closed-cell foam. Based on the one-dimensional stress wave theory and Voronoi model, a numerical model is developed to calculate the velocity of elastic wave and shock wave in metal foam. The effects of impact velocity and relative density of metal foam on the stress wave propagation in metal foams are explored respectively. The results show that both elastic wave and shock wave propagate faster in metal foams with larger relative density; with increasing the impact velocity, the shock wave propagation velocity increase, but the elastic wave propagation is not sensitive to the impact velocity.
\end{abstract}

\section{Introduction}

Metal foam is one kind of ideal lightweight energyabsorbing material, which can both bear great deformation and maintain relatively constant stress level under compression loading. It has been widely applied in various engineering fields, especially under impact environment $[1,2]$. Therefore, it is particularly important to study the dynamic characteristics under high-speed impact.

Research in dynamic mechanical behaviour of metal foams mainly includes three aspects, namely, the strain rate effect of base material, the inertia effect and the stress wave propagation in foams. The existing study pay much attention to the former two aspects. Some researchers point that the dynamic stress enhancement in metal foams under dynamic impact is mainly caused by inertia effect, other than strain rate effect of base material $[3,4]$, however, some other researchers hold the opposite point $[5,6]$. As for the stress wave propagation, some idealized stress strain models, such as RPPL, RLHPL, EPPL etc. [7-9] are proposed to describe the stress wave propagation in metal foams. However, the existing research is limited in the study of stress wave propagation velocity, due to the limitation of test methods. In this paper, a numerical model will be developed to calculate the propagation velocity of stress wave.

\section{Numerical modelling}

3D-Voronoi model with uniform cell wall thickness is constructed by Voronoi tessellations to represent aluminum alloy closed-cell foam. The bilinear strainhardening relationship is used to represent the true stressstrain relationship of the base material. The material properties are listed in Table1. The different relative densities are obtained by changing the thickness of cell

\footnotetext{
${ }^{a}$ Corresponding author: $p . x u e @ n w p u . e d u . c n$
}

walls, as follows

$$
\rho^{*} / \rho_{s}=\frac{\sum_{i=1}^{n} A_{i} \cdot t}{V}
$$

in which $\rho^{*}$ is the density of foam, $\rho_{s}$ is the density of base material, $A_{i}$ is the area of the cell wall and $V$ is the total volume of foam model. $n$ is the number of cell wall and $t$ is the cell wall thickness.

The foam model is set between two rigid plates, and the top plate moving towards the supporting plate at a prescribe velocity, as shown in Fig. 1. The dynamic compression process is implemented using commercialized software LS-DYNA.

\section{Results and discussion}

\subsection{Elastic wave propagation}

Under high-speed impact, elastic wave firstly forms in the metal foam and propagates from the impact side to the support side making the entire mental foam at the state of elastic deformation. Since the propagation of elastic wave costs some time to get through the metal foam, there exist time delay $\left(\Delta t_{e}\right)$ between the stress curves at the impact side and the support side, as is shown in Fig. 3 where the prescribed impact velocity is $200 \mathrm{~m} / \mathrm{s}$ and the relative density is 0.1 . Through dividing the length $(l)$ of the metal foam by the time delay, the propagation velocity of elastic wave in metal foams with a given relative density under certain impact velocity can be obtained as

$$
v_{e}=l / \Delta t_{e}
$$

Metal foams with different relative densities are compressed under four different impact velocities, 125, 150, 175 and $200(\mathrm{~m} / \mathrm{s})$ respectively, and the elastic wave propagation velocities are obtained through Eq. (2), as

This is an Open Access article distributed under the terms of the Creative Commons Attribution License 4.0, which permits unrestricted use, distribution, and reproduction in any medium, provided the original work is properly cited. 
Table 1. Material parameters of the base material.

\begin{tabular}{|l|l|l|l|l|}
\hline $\begin{array}{l}\text { Density } \\
(\mathbf{K g} / \mathbf{m 3})\end{array}$ & $\begin{array}{l}\text { Young's } \\
\text { modulus } \\
\text { (GPa) }\end{array}$ & $\begin{array}{l}\text { Tangent } \\
\text { modulus } \\
(\mathbf{G P a})\end{array}$ & $\begin{array}{l}\text { Yield } \\
\text { stress } \\
\text { (MPa) }\end{array}$ & $\begin{array}{l}\text { Poisson's } \\
\text { ratio }\end{array}$ \\
\hline 2700 & 69 & 0.47 & 76 & 0.35 \\
\hline
\end{tabular}

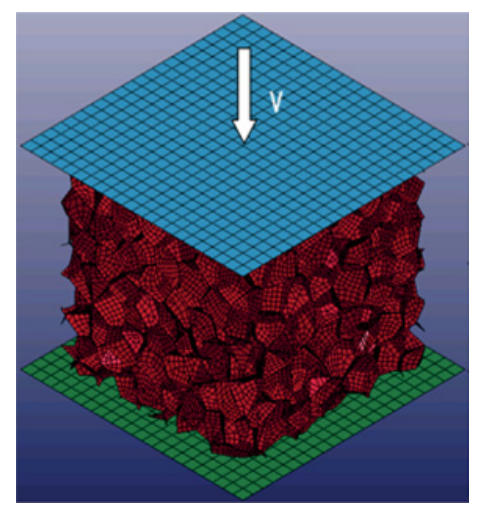

Figure 1. Finite element model of 3D-Voronoi foam.

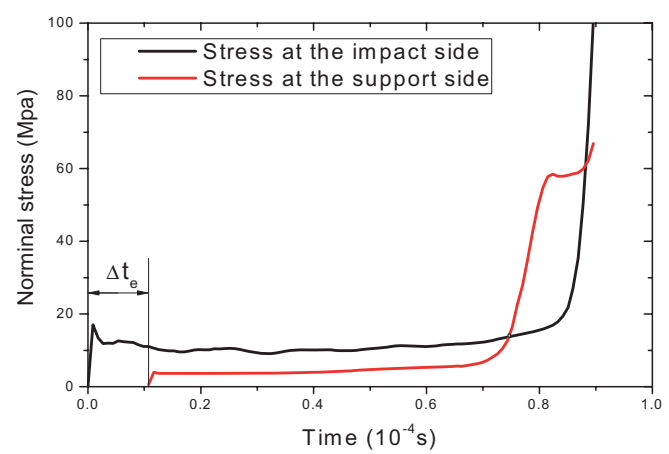

Figure 2. Stress vs. time curve for metal foam with the relative density of 0.1 .

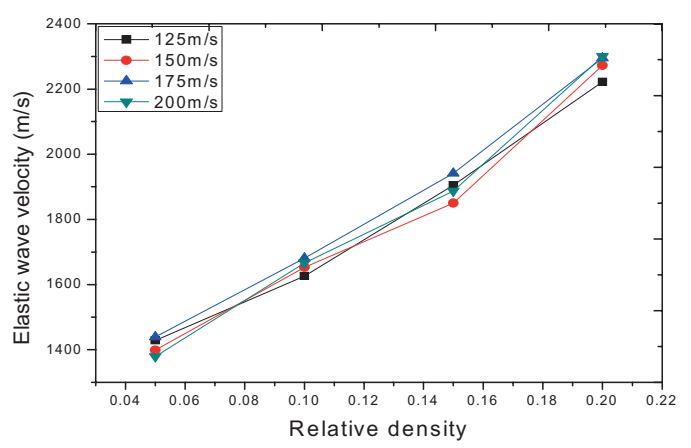

Figure 3. Elastic wave propagation velocity vs. relative density under various impact velocities.

is shown in Fig. 3. It is found that the elastic wave propagation velocity increase with the relative density become larger, but the effect of impact velocity on the propagation velocity of elastic wave is not obvious.

\subsection{Shock wave propagation}

When the impact load is large enough, the plastic collapse occurred, the deformation is localized and forms a narrow band, called a "shock front". The shock wave propagates
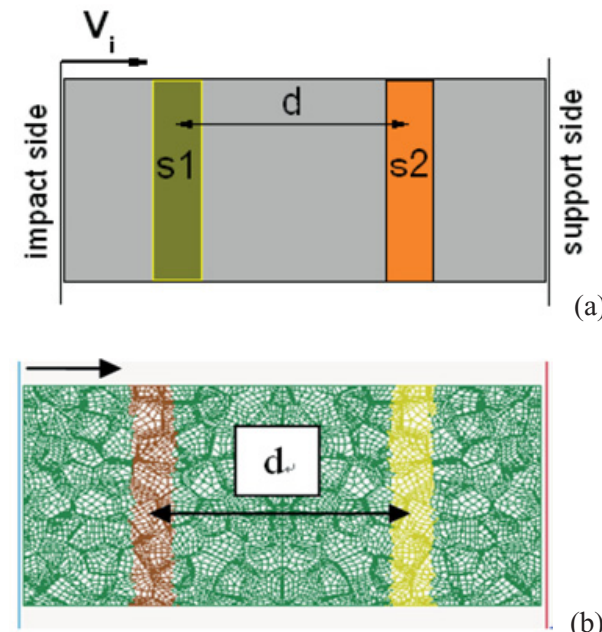

(b)

Figure 4. (a) Theoretical model, (b) Finite element model.

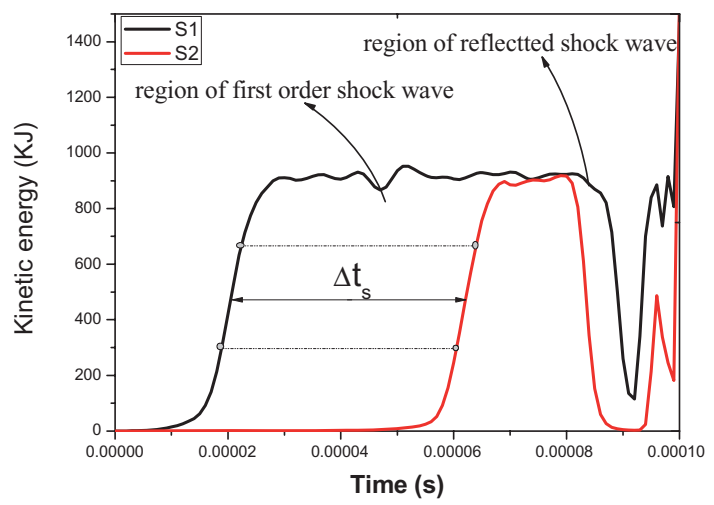

Figure 5. Kinetic energy vs. time curve for foam layer S1 and S2.

from the impact side to the support side. According to onedimensional stress wave theory, ahead of the shock front, metal foam is assumed to be at rest, and behind the shock front, metal foam is fully compacted. When the shock wave reaches to the support side, the shock wave will be reflected and the metal foam is compressed again.

\subsubsection{Calculation model of shock wave propagation velocity}

When the metal foam is compressed at a constant impact velocity, two layers (S1 and S2) of metal foam with the same layer width are chosen to be the object of study, as is shown in Fig. 4. Figure 5 shows the total kinetic energy vs. time curve of S1 and S2 respectively. According to the analysis above, during the shock front pass through the foam layer S1 and S2, the material particles in S1 and $S 2$ will experience three stages: before the shock front reaches, the layer of foam will be at rest and its total kinetic energy is zero; when the shock front is passing through, the particles are speed up from zero to a certain value and their total kinetic energy will experience a rise; when the shock leaves the layer, all particles in the layer have gained a certain velocity and their total kinetic energy will keep platform. By recording the time delay between S1 and S2, the shock wave propagation velocity in metal foams can be 


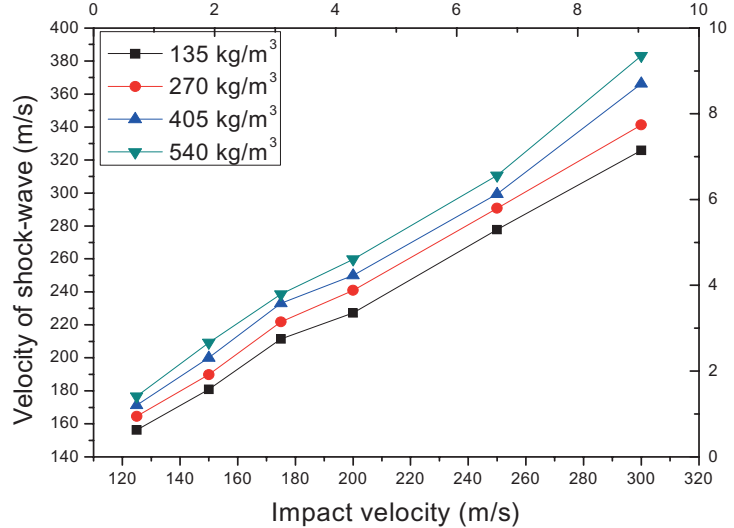

Figure 6. The velocity of shock wave vs. impact velocity for different density metal foams.

obtained as:

$$
v_{p}=d / \Delta t_{s} .
$$

Where $d$ is the distance between $\mathrm{S} 1$ and $\mathrm{S} 2$, and $\Delta t_{s}$ is the time for shock wave propagates from S1 to S2 which can be obtained from Fig. 5.

It can be seen from Fig. 5 that the kinetic energy curve alternately rising and falling, this is because when the shock wave arrives at the support side, surface reflection occurs and the metal foam undergo secondary compression process, in this paper, only the first order shock wave is discussed.

\subsubsection{Investigation into shock wave propagation velocity}

Figure 6 shows the shock wave propagation velocity vs. impact velocity curves for four different relative density metal foams, where the shock wave propagation velocity is calculated by Eq. (3). The diagram results show that the shock wave is dependent on the impact velocity and the density of the metal foam; with the increase of impact velocity the shock wave propagates faster in metal foam; for a given impact velocity, the shock wave propagates faster in metal foams with larger relative density.

\section{Summary}

Based on the one-dimensional stress wave theory and Voronoi model, a numerical model is developed investigate the stress wave propagation in metal foams. It is found that both elastic wave and shock wave propagate faster in metal foams with larger relative density; with increasing the impact velocity, the shock wave propagation velocity increase, but the elastic wave propagation is not sensitive to the impact velocity.

\section{References}

[1] G.X. Lu, T.X. Yu. Energy absorption of structures and materials(Cambridge University, Cambridge 2003)

[2] X.M. Qiu, J. Zhang, T.X. Yu, Int. J. Impact. Eng., 36, 1231-1241 (2009)

[3] G.W. Ma, Z.Q.Ye, Z.S. Shao, Int. J. Impact. Eng., 36, 6 (2009)

[4] Y.D. Liu, J.L. Yu, Z.J. Zheng, J.R. Li, Int. J. Solids. Struct., 46, 3988-3998 (2009)

[5] A. Paul, U. Ramamurty, Mater. Scleng. A, 281, 1-7 (2000)

[6] H. Zhao, Elnasri and H.J. Li. Adv. Eng. Mater, 8, 877883 (2006)

[7] S.R. Reid, C. Peng, Int. J. Impact. Eng., 19, 531-570 (1997)

[8] P.J. Tan, S.R. Reid, J.J. Harrigan, Z. Zou, S. Li, J. Mech. Phys. Solids, 53, 2206-2230 (2005)

[9] Z.J. Zheng, Y.D. Liu, J.L. Yu, S.R. Reid, Int. J. Impact. Eng., 42, 66-79 (2012) 